\title{
Syringe Decriminalization Advocacy in Red States: Lessons from the North Carolina Harm Reduction Coalition
}

\author{
David H. Cloud ${ }^{1} \cdot$ Tessie Castillo $^{2} \cdot$ Lauren Brinkley-Rubinstein $^{3,4} \cdot$ Manisha Dubey $^{4} \cdot$ Robert Childs $^{2}$
}

Published online: 8 May 2018

\begin{abstract}
Purpose of Review Syringe access programs (SAPs) are cornerstone harm reduction interventions for combatting the national opioid epidemic. The goal of this paper is to describe effective advocacy strategies for enacting syringe decriminalization legislation to foster the expansion of SAPs in high-need areas amidst political opposition.

Recent Findings Decades or research shows that SAPs prevent the transmission of HIV among people who inject drugs (PWID) and are a cost-effective tool for linking PWID to medical care, health education, and social services. In the USA, state laws criminalizing distribution and possession of syringes impede the expansion of SAPs into areas where they are sorely needed.

Summary In 2016, North Carolina became the first state to legalize SAPs with a Republican super majority. This paper distills strategies for community organizations seeking to advance syringe decriminalization legislation in politically conservative states with histories of prioritizing punitive sanctions over public health responses to drug use.
\end{abstract}

Keywords HIV $\cdot$ Harm reduction $\cdot$ North Carolina $\cdot$ Syringe access programs

\section{Introduction}

\section{HIV, Hepatitis C, and Overdoses in North Carolina}

The opioid epidemic is taking a grave toll on the health and longevity of communities across North Carolina. While rates have declined, HIV/AIDS is still an entrenched problem in North Carolina. The Tar Heel state ranks eighth in total number of new HIV/AIDS diagnoses in the country, which is four times the national average [1]. Statewide, between 2010 and

This article is part of the Topical Collection on The Global Epidemic

David H. Cloud

dcloud@emory.edu

1 Department of Behavioral Sciences and Health Education, Rollins School of Public Health, Emory University, 1518 Clifton Rd, Atlanta, GA 30322, USA

2 North Carolina Harm Reduction Coalition, Wilmington, NC, USA

3 Department of Social Medicine, University of North Carolina, Chapel Hill, NC, USA

4 Center for Health Equity Research, University of North Carolina, Chapel Hill, NC, USA
2014, reported cases of Hepatitis C (HCV) tripled with young adults (ages 20-39 years) comprising the largest share $(67.6 \%)$ of newly reported diagnoses. However, true HCV burden is certainly larger since an estimated $50 \%$ of people infected with the virus are unaware or undiagnosed [2]. People living in counties along North Carolina's western corner and eastern coast are most heavily burdened by HCV [3]. State officials estimate that the annual cost of treating $\mathrm{HCV}$ among Medicaid beneficiaries ballooned from 8 to 50 million dollars from 2013 to 2015 [4].

Sharing syringes, cookers, water, and other injection equipment is a leading risk factor for transmission of HIV and other blood-borne diseases [5]. Among North Carolinians, an estimated $9.4 \%$ of diagnosed HIV cases among men and $19.3 \%$ among women were acquired through IDU, respectively [6]. In 2014, the state's Division of Public Health reported that $84 \%$ of new acute $\mathrm{HCV}$ diagnoses were acquired via injection drug use (IDU) [3]. Opioid-related overdose deaths are also on the rise. Between 2010 and 2015, for example, heroin-related, fatal overdoses increased by $884 \%$, from 0.47 per 1000 deaths to 4.08 per 1000 deaths in North Carolina [6]. People who inject drugs (PWID) experience excess risk of overdose compared to people snorting, smoking, or ingesting opioids [7]. PWID also experience disparately high rates of 
untreated, chronic health problems, and bacterial infections that require care $[8,9]$. For example, in North Carolina, reported cases of endocarditis, a bacterial heart valve infection associated with injection drug use, increased more than 13-fold from 2009 to 2014 [3, 10, 11].

\section{Syringe Access Programs}

Syringe access programs (SAPs) are a cornerstone harm reduction intervention. Decades of scientific research demonstrate their effectiveness in curbing the spread of blood-borne diseases among people who inject drugs (PWID) by distributing sterile syringes and disposing of used ones [12-17]. Importantly, SAPs also provide benefits beyond communicable disease prevention. Most programs directly deliver or facilitate linkages to an array of health and social services, including drug treatment, overdose prevention, health education, chronic disease management, wound care, and assistance obtaining health insurance, housing, food, and social entitlements. Increasingly, SAPs train and supply PWID with kits for administering naloxone, a highly effective antidote for reversing respiratory failure from opioid overdose [18]. Studies have shown that SAP participants are significantly more likely to seek drug treatment than those not using the program $[19,20]$. Finally, empirical evidence has confirmed that SAPs do not increase levels of drug use or breed crime, a common misconception of policy opponents [21,22].

The Centers for Disease Control and Prevention (CDC), American Public Health Association, American Society on Addiction Medicine, National Association of County and City Health Officials, among many other US health authorities have urged state and local governments to create and expand SAPs as an essential strategy for addressing HIV, HCV, and other harms associated with IDU [23-26]. Yet, according to surveys conducted by the North American Syringe Exchange Network, there are only 264 SAPs operating nationwide [27]. These vital programs are non-existent or insufficiently scaled to reach people who would benefit from their services, especially those living outside urban centers. In 2015, the CDC found that $69 \%$ of SAPs are located in cities, compared to only 20 and $9 \%$ in rural and suburban areas, respectively. They also found that only $37 \%$ of programs in rural areas offer naloxone kits, compared with $61 \%$ of urban programs [28]. During a 2016 public briefing speaking to the results of this survey, former CDC director, Dr. Tom Frieden, called for expanded SAP coverage nationwide.

"[SAPs] help prevent thousands of cases of HIV and save literally hundreds of millions of dollars. However...there is still a large unmet need for sterile injection equipment. This finding reinforces the concern that outbreaks could occur in people who inject drugs in areas where sources of sterile equipment are limited."

\section{Legal Barriers to SAPs and Harm Reduction}

Since the late 1980s, political opposition to harm reduction has hindered the adoption of laws necessary for establishing SAPs in high-need areas. Broadly, policymakers' resistance to SAPs is rooted in an array of interrelated factors: moralistic condemnation of addiction and psychoactive substances, dominance of abstinence-only-based philosophies within mainstream treatment systems, misconceptions about risks of increased drug use and crime, and forces of structural racism giving rise to the US war on drugs and mass incarceration [29-32]. In prior decades, as the HIV epidemic began spreading among networks of PWID and Black communities in major cities, support for SAPs among lawmakers was sorely lacking [29]. Since, except for a brief period between 2009 and 2011, federal law prohibited federal funding for SAPs. While the AIDS epidemic was intensifying, the US Department of Health and Human Services (HHS) denied finances to support SAPs on the grounds that there was no conclusive evidence demonstrating their effectiveness and safety. Yet, in the same breath, federal officials also prohibited the use of federal dollars to support SAP research, which significantly hampered the progress of activists and scientists committed to piloting and testing the effects of SAPs [30].

Opposition to SAPs has waned at the federal level in recent years. A shift in the demographic and geographic burden of drug-related harms from urban communities of color into rural and suburban epicenters of white America is prompting government responses that are comparatively more compassionate and treatment-oriented than the wave of policing and incarceration waged on Black communities in prior decades. In 2016, with Republican leadership, Congress effectively lifted the federal ban on SAPs by authorizing states and local governments to use federal grants for more costly aspects of operating a program, such as rent, gas, and staffing, while still forbidding purchase of sterile injection equipment [33]. Shortly thereafter, HHS and the CDC issued guidance for states and local agencies to request federal support for SAPs in their jurisdiction [34].

However, state laws criminalizing possession of syringes and enforcement tactics prioritizing arrest, prosecution, and incarceration in response to drug-use behaviors are structural barriers that preventing health departments and harm reduction organizations from capitalizing on changes in federal policy to establish SAPs in high-needs areas. As of 2017, SAPs remain illegal in 29 states, all of which have Republican-controlled legislatures [35]. Southern states with longstanding disparities in HIV, viral hepatitis, and 
other blood-borne diseases are among the slowest to pursue SAP legislation [35-39]. Importantly, four additional states with Republican super majorities, Florida, North Dakota, Tennessee, and Utah passed bills authorizing the operation of SAPs. Yet, other proposals have continuously failed to gain traction in other states with disproportionately high rates of HIV, including Georgia, Alabama, Mississippi, South Carolina, and Texas. Without legislative action, communities that have long-endured HIV disparities and those on the cusp of unprecedented HIV and HCV outbreaks are imperiled.

\section{Harm Reduction Advocacy in Red States}

On July 11, 2016, North Carolina became the first state to pass a bill authorizing the operation of SAPs with a Republican super majority [40]. The North Carolina Harm Reduction (NCHRC), a small non-profit organization led by co-authors Castillo and Childs, orchestrated a novel advocacy campaign that resulted in this improbable victory. The law includes provisions designed for operating SAPs across urban, suburban, and rural terrains. One provision allows harm reduction organizations, AIDS Service Organizations, Faith Centers, community-based organizations, and health departments to start a "needle and hypodermic syringe exchange program" [40]. The law does not require organizations to acquire state or local approval before starting a SAP. Rather, programs are only required to notify state health officials and coordinate with local law enforcement agencies [40]. This flexibility has empowered coalitions of advocates and health service providers to promptly establish programs where they are most needed. In contrast, other states, such as Kentucky, only permit local health departments to operate SAPs after receiving local health board approval [41]. However, such rules risk crowding out organizations with the closest relationships, established trust, and deepest expertise delivering health services to PWID, sex workers, and other marginalized groups. Permitting diverse organizations to establish programs allowed NCHRC and other non-profits to mobilize coalitions of advocates and service providers that were equipped to start programs shortly after the law enacted.

Any entity starting a program is expected to deliver an array of services, as described in the law. These include the following: disposal of used syringes, distribution of free, sterile injection equipment, educational materials on overdose, HIV, and HCV prevention; access to naloxone kits; and personal consultations and treatment referrals for substance use and psychiatric conditions [40]. Specifying the types of services that SAPS are expected to provide has helped ensure that organizations starting programs engage in careful planning processes to ensure programs promote a holistic approach to service delivery.
SAPs only work when participants feel empowered to access services without fear of reprisal. Indeed, research and experience show that people are less likely to utilize SAP services and more likely to engage in riskier injection behaviors when they fear police and incarceration [42-44]. Therefore, immunity from arrest and prosecution for behaviors related to drug use is essential. North Carolina's law gives SAP participants, volunteers, and staff immunity from criminal sanctions for possession of injection supplies and residual amounts of drugs. However, the law does require people stopped by police to show officers an identification card to verify participation in a SAP to avoid arrest and does not imposed civil liability on officers who arrest a SAP participant [40].

Another key provision authorizes programs to distribute quantities of syringes and injection equipment based on a participant's level of need and not the number of used syringes returned for disposal [40]. Research shows, more restrictive, one-for-one policies are less effective in reducing HIV transmission than needs-based policies by increasing the chances that people share or reuse equipment [45-47]. Thus, NCHRC drafted language explicitly stating that syringes and other injection supplies would be free and distributed in quantities sufficient to ensure that injection equipment is not shared or reused.

While convincing fiscally conservative, elected officials to budget tax dollars for providing PWID free syringes is politically difficult, advocates and public health leaders should strive to include statutory provisions that allow harm reduction organizations and health departments to utilize state and local funding for service delivery is important for scaling and sustaining programs. NCHRC has made incremental, but significant progress in acquiring public funding for SAPs. In 2015, NCHRC reluctantly conceded to inserting a provision into the syringe decriminalization bill that precluded use of all public funding for SAPs. Lawmakers would only bring the bill to the floor for a vote with a promise that the government would not bear the cost. Yet, after a couple years of demonstrated success in operating SAP across the state, NCHRC was able to successfully amend the syringe bill to permit city and local governments to financially support for SAPs, which empowers local health departments, city councils, and counties to spend their own revenue to start/support programs [48].

Collecting data is critical for monitoring SAP implementation, assessing impact, and converting opponents to supporters with evidence of impact. North Carolina's law includes a provision delegating responsibility of monitoring implementation and collecting data on service utilization to the Division of Public Health [40]. Nearly 18 months since Governor McCrory signed the syringe decriminalization bill into law, 16 different organizations have started 23 different 
SAPs, serving a total of 31 counties across North Carolina. While additional studies are needed, program records suggest that SAPs and decriminalization are making a difference in North Carolina. Altogether, these programs have distributed a total of 1,024,226 sterile syringes to 3230 participants and collected and disposed of more than 431,985 used syringes. North Carolina's SAPs have also trained more than 2600 people of overdose prevention and handed out more than 5401 naloxone kits, made 3581 referrals into treatment.

\section{Replicable Advocacy Tactics}

Harm reduction activism that depends solely on Democratic leadership as a vehicle for drug policy reform too often falls short of achieving legislative change in deep red states. In North Carolina, prior attempts to legislate increased access to sterile syringes for PWID failed six times in North Carolina between 1997 and 2013. In 2011, NCHRC took its first shot at syringe decriminalization by drafting a bill and finding support in a progressive democratic sponsor. Despite a valiant effort to bolster voter support and educate lawmakers, the bill flopped for two main reasons: the 2010 midterm elections had just ushered a Republican super majority into control, and two closely aligned, powerful, and conservative leaning lobbying groups, the North Carolina Sheriff's Association and North Carolina Association of Chiefs of Police, adamantly opposed syringe decriminalization out of the gates. From this experience, NCHRC realized that maneuvering drug policy proposals thorough its legislature would require a Republican sponsor and vocal support from law enforcement leaders. Reflecting on NCHRC's advocacy campaign, we offer guidance to activists and public health leaders fighting to pass legislation conducive to starting and expanding SAPs in conservative political environments.

\section{Community Organizing and Coalition Building}

Effective advocacy campaigns start with grassroots organizing and coalition building guided by the voices of people who use drugs and other marginalized groups. NCHRC started its syringe decriminalization efforts by bringing together key stakeholder groups, including people who use drugs, sex workers, veterans, migrant workers, and people of transgender experience to plan and implement community outreach and advocacy strategies. As part of strategy, NCHRC organized an HIV/Syringe Decriminalization advocacy day, a Sex Work Summit, and the first Southern Harm Reduction Conference. As NCHRC's coalition of supporters grows, maintaining a comprehensive list serve of individuals, organizations, policymakers, business leaders, and other community stakeholders who support NCHRC's policy goals of overdose prevention, syringe decriminalization, and criminal justice reform has proved critical. NCHRC relies on this list serve for disseminating petitions, raising funds, planning community events, educating members on reforms and where to access direct service, and mobilizing voters during legislative sessions. In 2016, NCHRC depended on the list serve to send an emergency alert that mobilized thousands of coalition members who made calls and sent emails to the lawmaker who was contemplating reversing a prior commitment to introduce the syringe decriminalization bill. Without this flurry of phone calls from his constituents, this bill may not have advanced any further that year.

\section{Garnering Law Enforcement Support}

Historically, harm reduction advocates have historically considered law enforcement entities as foes and not allies in advocating for decriminalization of drug use behaviors. Indeed, studies show that fear of police and aggressive policing crackdowns increase risky behaviors associated with transmission of blood-borne diseases among PWID. However, NCHRC developed strategies to overcome historical challenges and pass harm reduction legislation by building new relationships with law enforcement. As explained below, the effectiveness of these strategies is reflected in text conveying the legislative intent of the bill, which outlines three goals: reducing the spread of HIV, AIDS, viral hepatitis, and other blood-borne diseases; decreasing needle stick injuries to law enforcement officers and other emergency personnel, and encouraging individuals who inject drugs to enroll in evidence-based treatment [40].

\section{Needle Sticks and Occupational Health}

In 2012, as a first step, NCHRC decided to travel around the state and educate police officers about HIV, HCV, and needle stick prevention. An estimated one in three police officers get stuck with a syringe during a body search during their careers. Prior studies show that police officers develop increasingly favorable attitudes toward SAPs and syringe decriminalization, after receiving educational trainings communicating how syringe decriminalization reduces officers' personal risk of needle sticks, and SAPs effectiveness in getting people into treatment without arrest [49]. NCHRC hired a Law Enforcement Safety Advocate to schedule and coordinate needle stick prevention training sessions with police departments across the state. They started by reaching out to departments that provide training for crisis intervention teams (CITs), which are collaborative teams of officers trained to prevent violence, avoid arrests, and facilitate appropriate linkages to psychiatric services when responding to calls involving a person in psychosis or emotional distress [51]. CIT trainings were a natural forum to build support for SAPs. While the training sessions were primarily about needle stick prevention, 
NCHRC educated attendees on the benefits of SAPs and decriminalization. In doing so, they intentionally used the term syringe access (not "exchange") program to emphasize that SAPs do more than swap dirty syringes for clean ones.

\section{Linkages to Treatment and Medical Services}

Prior to NCHRC trainings, most police officers did not know that SAPs are also highly effective in getting people into treatment among providing other benefits. Police officers expressed their own frustrations with continuously arresting people for drug-related crimes and became more supportive of SAPs after learning that they do more than exchange injection equipment. In fact, an analysis of surveys administered to 350 CIT officers in North Carolina found that $60 \%$ of officers said that syringe decriminalization would benefit the community and law enforcement officers, after participating NCHRC trainings [49]. These trainings helped NCHRC achieve its first small step toward syringe decriminalization. In 2013, NCHRC compromised to pass a law giving people immunity from criminal charges if disclosing possession of a syringe prior to a body search. Two years later, trying again for full syringe decriminalization, the legislature and police lobbyist agreed to authorize harm reduction organizations to collect used syringes [40].

Recruiting a Republican Bill Sponsor Demonstrating support from a key constituency is critical to gaining legislative support and sponsorship. In the case of the SAP bill, NCHRC used surveys from law enforcement that demonstrated support for SAPs in order to convince a Republican legislator, a former Chief of Police, to sponsor a bill. This lawmaker had previously sponsored a Good Samaritan bill extending criminal immunity to anyone calling 911 in response to overdose. To gain support of other key legislators, NCHRC invited them to meetings in their districts hosted by influential members of their community, such as public health directors, faith leaders, and sheriffs. NCHRC collected and disseminated quotes from law enforcement leaders across the state in support of harm reduction and syringe decriminalization. These quotes proved to be a powerful advocacy tool for garnering support from lawmakers and other police departments.

Data Collection and Academic Partnerships Collaborations between activists and academic researchers play an important role in driving policy change in North Carolina. For example, since law enforcement agencies started carrying and administering naloxone, NCHRC has tracked total lives saved through overdose reversals. Presenting data on lives being saved via police officer naloxone administrations to lawmakers has been invaluable for building political support for syringe decriminalization and other harm reduction measures. Additionally, in partnership with Duke University's nursing school, NCHRC surveyed local pharmacies and found that $64 \%$ of owners were willing to sell syringes to people who inject drugs, but less than $20 \%$ were willing to have their stores serve as a biohazard collection site for used syringes.

\section{Conclusion}

Harm reduction activists have a longer history of clashing than collaborating with conservative lawmakers and police departments. Given this historical context and existing power dynamics, working toward drug policy reform through unconventional partnerships with law enforcement will inevitably pose complicated ethical dilemmas for harm reduction activists. There are situations in which the goals of law enforcement and harm reductionists clearly do not align. In these situations, NCHRC's rule of thumb is "first, do no harm." We partnered with law enforcement only on goals where we could both agree on the result and made sure than any compromises made did not cause more harm, even if there was a benefit in another area. In time, the areas in which we agreed grew in North Carolina, mostly due to law enforcement becoming increasingly comfortable with harm reduction as a philosophy. Advocates and lawmakers committed to drug policy reform should focus attention on reducing stigma and increasing access to treatment and medical insurance, instead of overemphasizing any one particular drug used, such as devising solutions to the opioid issues alone, which mostly affect white consumers. SAPs are an essential tool for addressing today's opiate epidemic. Criminalization and fear of police are formidable barriers to creating and operating effective SAPs, even in cities where they are legalized. Yet, the bottom line is that SAPs cannot achieve their goals without some level of buy-in from law enforcement. In North Carolina, and other politically conservative jurisdictions, law enforcement agencies exert significant influence over legislative priorities, especially in the area of drug use. Educating police leaders on the occupational health benefits of SAPs for officers and effectiveness in connecting PWID to treatment is a promising strategy for building the necessary political support for syringe decriminalization and a step toward harm-reduction-oriented policy. Across the country, a growing number of local criminal justice systems are looking for solutions beyond arrest and incarceration to problems rooted in drug use, poverty, and homelessness. Bridging political divides by engaging police leaders as advocates for sounder drug policy is complicated and imperfect, but timely and necessary for driving structural change in the Deep South. 


\section{Compliance with Ethical Standards}

Conflict of Interest The authors declare that they have no conflict of interest.

Human and Animal Rights and Informed Consent This article does not contain any studies with human or animal subjects performed by any of the authors.

\section{References}

1. Zibbell JE, Iqbal K, Patel RC, Suryaprasad A, Sanders KJ, MooreMoravian $\mathrm{L}$, et al. Increases in hepatitis $\mathrm{C}$ virus infection related to injection drug use among persons aged $\leq 30$ years-Kentucky, Tennessee, Virginia, and West Virginia, 2006-2012. MMWR Morb Mortal Wkly Rep. 2015;64(17):453-8.

2. Onofrey S, Aneja J, Haney GA, Nagami EH, DeMaria A, Lauer $\mathrm{GM}$, et al. Underascertainment of acute hepatitis $\mathrm{C}$ virus infections in the US surveillance system a case series and chart review. Ann Intern Med. 2015;163(4):254-61.

3. Rhea S, Fleischauer A, Foust E, Davies M. Hepatitis C in North Carolina two epidemics with one public health response. N C Med J. 2016;77(3):190-2.

4. Centers for Disease Control and Prevention. HIV Surveillance Report, 2015; vol. 27. http://www.cdc.gov/hiv/library/reports/hivsurveillance.html. Published November 2016. Accessed October 24, 2017.

5. AIDS Vu. North Carolina Profile. https://aidsvu.org/state/northcarolina/ Accessed 20 Oct. 2017.

6. Proescholdbell S. Opioid overdose and North Carolina's public health and prevention strategies. https://www.ncleg.net/ DocumentSites/Committees/NCCFTF/Presentations/2016-2017/ Overdose \%20Update\%20Proescholdbell\%2010-20-16.pdf. Accessed 20 Oct. 2017.

7. Mathers BM, Degenhardt L, Bucello C, Lemon J, Wiessing L, Hickman M. Mortality among people who inject drugs: a systematic review and meta-analysis. Bull World Health Organ. 2013;91(2):102-23.

8. Gordon RJ, Lowy FD. Bacterial infections in drug users. N Engl J Med. 2005;353(18):1945-54.

9. Altice FL, Kamarulzaman A, Soriano VV, Schechter M, Friedland GH. Treatment of medical, psychiatric, and substance-use comorbidities in people infected with HIV who use drugs. Lancet. 2010;376(9738):367-87.

10. Keeshin SW, Feinberg J. Endocarditis as a marker for new epidemics of injection drug use. Am J Med Sci. 2016;352(6):609-14.

11. North Carolina HIV/STD/Hepatitis Surveillance Unit. (2017). 2016 North Carolina HIV/STD/hepatitis surveillance report. North Carolina Department of Health and Human Services, Division of Public Health, Communicable Disease Branch. Raleigh, North Carolina. http://epi.publichealth.nc.gov/cd/stds/figures/std16rpt_ rev2.pdf. Accessed 1 Oct. 2017.

12. Gibson DR, Flynn NM, Perales D. Effectiveness of syringe exchange programs in reducing HIV risk behavior and HIV seroconversion among injecting drug users. AIDS. 2001;15(11):1329-41.

13. Bastos FI, Strathdee SA. Evaluating effectiveness of syringe exchange programmes: current issues and future prospects. Soc Sci Med. 2000;51(12):1771-82.

14. Heimer R, Khoshnood K, Bigg D, Guydish J, Junge B. Syringe use and reuse: effects of syringe exchange programs in four cities. $\mathrm{J}$ Acquir Immune Defic Syndr. 1998;18:S37-44.
15. Watters JK, Estilo MJ, Clark GL, Lorvick J. Syringe and needle exchange as HIV/AIDS prevention for injection drug users. JAMA. 1994;271(2):115-20.

16. Wodak, A., Cooney, A., \& World Health Organization. (2004). Effectiveness of sterile needle and syringe programming in reducing HIV.

17. Holtzman D, Barry V, Ouellet LJ, Des Jarlais DC, Vlahov D, Golub ET, et al. The influence of needle exchange programs on injection risk behaviors and infection with hepatitis $\mathrm{C}$ virus among young injection drug users in select cities in the United States, 1994-2004. Prev Med. 2009;49(1):68-73.

18. Clark AK, Wilder CM, Winstanley EL. A systematic review of community opioid overdose prevention and naloxone distribution programs. J Addict Med. 2014;8(3):153-63.

19. Strathdee SA, Ricketts EP, Huettner S, Cornelius L, Bishai D, Havens JR, et al. Facilitating entry into drug treatment among injection drug users referred from a needle exchange program: results from a community-based behavioral intervention trial. Drug Alcohol Depend. 2006;83(3):225-32.

20. Strathdee SA, Celentano DD, Shah N, Lyles C, Stambolis VA, Macalino G, et al. Needle-exchange attendance and health care utilization promote entry into detoxification. Journal of Urban Health. 1999;76(4):448-60.

21. Marx MA, Crape B, Brookmeyer RS, Junge B, Latkin C, Vlahov D, et al. Trends in crime and the introduction of a needle exchange program. Am J Public Health. 2000;90(12):1933-6.

22. Galea S, Ahern J, Fuller C, Freudenberg N, Vlahov D. Needle exchange programs and experience of violence in an inner city neighborhood. J Acquir Immune Defic Syndr. 2001;28(3):282-8.

23. The Centers for Disease Prevention and Control. Syringe Services Programs (SSPs) for People Who Inject Drugs (PWID). Available at https://www.cdc.gov/nchhstp/dear_colleague/2016/dcl-033016syringe-services-programs-for-pwid.html. Accessed November 8 , 2017.

24. The American Public Health Association. Policy Statement. Syringe and Needle Exchange and HIV Disease.

25. American Society of Addiction Medicine. Public Policy Statement on Access to Sterile Syringes and Needle (2005). https://www. asam.org/docs/default-source/public-policy-statements/1accesssyringes-12-00.pdf?sfvrsn=90a8c1b2_0. Accessed 20 Oct. 2017.

26. National Association of City and County Health Officials. Statement of Policy. "Syringe Service Programs" May 2009/ https://www.naccho.org/uploads/downloadable-resources/Policyand-Advocacy/05-09-Syringe-Services-Programs.pdf. Accessed 20 Oct. 2017.

27. North American Syringe Exchange Network. https://nasen.org/ directory/. Accessed 20 Oct. 2017.

28. Wejnert C. Vital signs: trends in HIV diagnoses, risk behaviors, and prevention among persons who inject drugs-United States. MMWR Morb Mortal Wkly Rep. 2016;65:1336-42.

29. Heller D, Paone D. Access to sterile syringes for injecting drug users in new York City: politics and perception (1984-2010). Substance Use \& Misuse. 2011;46(2-3):140-9.

30. Des Jarlais DC, McKnight C, Goldblatt C, Purchase D. Doing harm reduction better: syringe exchange in the United States. Addiction. 2009;104(9):1441-6.

31. Friedman SR, Southwell M, Bueno R, Paone D, Byrne J, Crofts N. Harm reduction - a historical view from the left. International Journal of Drug Policy. 2001;12(1):3-14.

32. Buchanan D, Shaw S, Ford A, Singer M. Empirical science meets moral panic: an analysis of the politics of needle exchange. J Public Health Policy. 2003:427-44.

33. The Consolidated Appropriations Act (2016). Division H, Sec 520. https://www.congress.gov/114/bills/hr2029/BILLS-114hr2029enr. pdf. Accessed 8 Nov. 2017. 
34. Department of Health and Human Services Implementation Guidance to Support Certain Components of Syringe Services Programs, 2016. https://www.hiv.gov/sites/default/files/hhs-sspguidance.pdf. Accessed 8 Nov. 2017.

35. National Conference of State Legislatures. State Partisan Composition in 2017. http://www.ncsl.org/Portals/1/Documents/ Elections/Legis_Control_2017_November\%208th_9am.pdf. Accessed 8 Nov. 2017.

36. Taussig JA, Weinstein B, Burris S, Jones TS. Syringe laws and pharmacy regulations are structural constraints on HIV prevention in the US. AIDS. 2000;14:S47-51.

37. Beletsky L, Cochrane J, Sawyer AL, Serio-Chapman C, Smelyanskaya M, Han J, et al. Police encounters among needle exchange clients in Baltimore: drug law enforcement as a structural determinant of health. Am J Public Health. 2015;105(9):1872-9.

38. Bramson H, Des Jarlais DC, Arasteh K, Nugent A, Guardino V, Feelemyer J, et al. State laws, syringe exchange, and HIV among persons who inject drugs in the United States: history and effectiveness. J Public Health Policy. 2015;36(2):212-30.

39. Preventing HIV and Hepatitis C Among people who inject drugs: public funding for syringe services programs makes the difference. Issue brief. April 2017.amfAR. The Foundation for AIDS Research http://www.amfar.org/uploadedFiles/ amfarorg/On the Hill/ amfAR_SSP_Issue_Brief_April_2017-update.pdf. Accessed 8 Nov. 2017.

40. General Assembly of North Carolina. House Bill 972 / S.L. 2016 88. http:/www.ncleg.net/Sessions/2015/Bills/House/HTML/ H972v8.html. Accessed 8 Nov. 2017.

41. Kentucky Harm Reduction and Syringe Exchange Program (HRSEP) Guidelines for Local Health Departments Implementing Needle Exchange Programs. http://chfs.ky.gov/NR/rdonlyres/
E 7F BC 3 DC-E 365 - 4CD 8-93B F - FA 797052303 A/ $0 /$ HRSEPGuidelinesLongVersionFINAL.pdf. Accessed 8 Nov. 2017.

42. Kerr T, Small W, Wood E. The public health and social impacts of drug market enforcement: a review of the evidence. International journal of drug policy. 2005;16(4):210-20.

43. Burris S, Blankenship KM, Donoghoe M, Sherman S, Vernick JS, Case P, et al. Addressing the "risk environment" for injection drug users: the mysterious case of the missing cop. The Milbank Quarterly. 2004;82(1):125-56.

44. Cooper H, Moore L, Gruskin S, Krieger N. The impact of a police drug crackdown on drug injectors' ability to practice harm reduction: a qualitative study. Soc Sci Med. 2005;61(3):673-84.

45. Bluthenthal RN, Ridgeway G, Schell T, Anderson R, Flynn NM, $\mathrm{Kral}$ AH. Examination of the association between syringe exchange program (SEP) dispensation policy and SEP client-level syringe coverage among injection drug users. Addiction. 2007;102(4): 638-46.

46. Bluthenthal RN, Malik R, Grau LE, Singer M, Marshall P, Heimer R. Sterile syringe access conditions and variations in HIV risks among drug injectors in three cities. Addiction. 2004;99:1136-46.

47. Kral AH, Anderson R, Flynn NM, Bluthenthal RN. Injection risk behaviors among clients of syringe exchange programs with different syringe dispensation policies. Journal of Acquired Immune Deficiency Syndrome. 2004;37:1307-12.

48. Strengthen Opioid Misuse Prevention (STOP)Act. https://www. ncleg.net/Sessions/2017/Bills/Senate/PDF/S175v1.pdf. Accessed 8 Nov. 2017.

49. Davis CS, Johnston J, de Saxe Zerden L, Clark K, Castillo T, Childs R. Attitudes of North Carolina law enforcement officers toward syringe decriminalization. Drug Alcohol Depend. 2014;144:265-9. 